\title{
Comparison of two different restoration materials and two different implant designs of implant-supported fixed cantilevered prostheses: A 3D finite element analysis
}

\author{
Ahmet Kursad Culhaoglu, Serhat Emre Ozkir ${ }^{1}$, Gozde Celik², Hakan Terzioglu³ \\ Departments of Prosthodontics, Kirikkale University, Faculty of Dentistry, Kirikkale, \\ ${ }^{1}$ Afyon Kocatepe University, Faculty of Dentistry, Afyonkarahisar, ${ }^{2}$ Bezmialem University, Faculty of \\ Dentistry, Fatih, Istanbul, ${ }^{3}$ Ankara University, Faculty of Dentistry, Besevler, Ankara, Turkey
}

\author{
Address for correspondence: \\ Dr. Ahmet Kursad Culhaoglu, \\ Doktor Mediha Eldem Sokak. \\ No: 70/11 Kocatepe, Ankara, Turkey. \\ E-mail: ahmetculhaoglu@hotmail.com
}

\begin{abstract}
Purpose: A key factor for the success or failure of a dental implant is the manner of stresses transferred to the surrounding bone. Parallel to this situation, cantilever extensions where it is not possible to place another implant, would cause greater stress and it should be avoided if possible. Manufacturers and clinicians try to develop new implant designs and superstructure materials to reduce the stresses around the implant and supporting bone tissue. This study analyzed the influence of superstructure materials and implant designs on stress distribution around dental implants supporting cantilever restoration under loading conditions. Materials and Methods: Three-dimensional finite element models of a 3-unit cantilever bridge were subjected to $150 \mathrm{~N}$ occlusal load to evaluate two different superstructure materials (conventional metal ceramic, fiber reinforced composite) and two different implant designs, cylinder type (Institut Straumann AG, Waldenburg, Switzerland) and cylinder type with micro threads around implant neck (Astra Tech AB, Mölndal, Sweden). To evaluate the distribution of stresses within the bone surrounding the implants, 3-dimensional finite element analysis was conducted using four mathematical models of unilateral 3-unit cantilever fixed partial dentures supported by two implants. Results: The stress distribution patterns and stress values were similar and stress concentrations were similar in both restoration materials. The highest stress concentrations were around the adjacent ITI implant, which supports the conventional metal porcelain restoration. Conclusions: Although, there was no significant difference in stress distribution between fiber reinforced composite (FRC) and conventional metal porcelain, stress values were lower in FRC restorations. The Astra-Tech micro-thread design reduced the stress that was distributed throughout the implant body, but it should be noted that the peak stress was still present on the implant neck.
\end{abstract}

Key words

Cantilevers, fiber reinforced composites, finite element analysis, implant design

\section{INTRODUCTION}

Since dental implants were introduced for the rehabilitation of patients in the late 1960s, an awareness demand for this form of therapy has increased. The use of implants has revolutionized dental treatment modalities and provided excellent long-term results. The clinical success of dental implants depends largely on initial stability and long-term osseointegration with optimal stress distribution that provides lasting incorporation with bone and also on implant design features such as materials, geometry. ${ }^{[1]}$

\begin{tabular}{|l|l|}
\hline \multicolumn{2}{|c|}{ Access this article online } \\
\hline Quick Response Code: & Website: \\
\hline & www.ejgd.org \\
\cline { 2 - 3 } & \\
\hline & DOI: \\
\hline
\end{tabular}

A key factor for the success or failure of a dental implant is the manner in which stresses are transferred to the surrounding bone. Manufacturers try to develop implant designs and materials that reduce the stresses around the implant. Considering the expanded indications for implants and changing clinical protocols, the relationship between implant design and load distribution at the implant-bone interface continues to be an important issue. ${ }^{[2]}$ From an engineering perspective, it is important to design the implant with a geometry that will minimize the peak bone stress caused by loading. ${ }^{[3]}$

To accelerate osseointegration and to control the stresses in the bone, the most common approach is alteration of dental implant designs such as macro-design and micro-design (surface alterations). ${ }^{[4-7]}$ Implant manufacturers have produced different implant designs to reduce the stresses around the implant and supporting bone tissue, and have particularly attempted to minimize stress magnifications around the collar of 
the implant, in cortical bone and transfer such stresses to the apical site.

Implant designs incorporate thread-cutting profiles to reduce interfacial shear stress such as a $15^{\circ}$ thread profile (ITI/Straumann, Institut Straumann AG, Waldenburg, Switzerland) with a rounded tip to reduce shear forces at the tip of the thread. Other thread designs (Microthread ${ }^{\mathrm{TM}}$ Astra Tech AB, Mölndal, Sweden) have focused on reducing the surrounding transcortical shear forces by reducing the height of the thread profile (thus reducing the contribution of any one thread) with an increase in the number of threads per unit area of the implant surface. ${ }^{[3,8]}$ The collar region of implants are designed with micro threads may offer optimal load distribution and lower stress values at the critical point of implant-bone interface, marginal cortical bone where peak stresses occur.

Superstructures of the implants may also affect the stress distribution. Because of the lack of micro-movement of osseointegrated implants, most of the force distribution is concentrated on the crest of the ridge, and this may lead to bone resorption and subsequent loss of the implant. It has been suggested that stress-absorbing or load-damping systems be incorporated into the superstructures supported by osseointegrated implants, to reduce loading on the implant due to the lack of viscoelasticity at the bone-implant interface. ${ }^{[9]}$ An alternative to metal-ceramic and full ceramic restorations in implant-supported fixed partial denture (FPD) is fiber reinforced composite (FRC). ${ }^{[10,11]} \mathrm{FRC}$ has been suggested to absorb energy from the masticatory cycle due to the lower flexural modulus of the material. ${ }^{[12]}$

Anatomical limitations such as maxillary sinus or mental foramen/inferior alveolar nerve would preclude insertion of implants. Unfavorable local conditions of the residual edentulous ridges may lead to treatment of a partially edentulous site with cantilever fixed prosthesis. As a simple and economical procedure, edentulous ridges next to implants may be reconstructed by means of cantilevers or pontics. Some mechanical studies have demonstrated that the cantilever FPDs supported by dental implants could induce excessive stress concentration in the supporting alveolar bone. This excessive stress concentration might facilitate bone resorption under the functional occlusal loads, especially in the cervical region of the implants, and thus compromise the longevity of the implant-supported prostheses. ${ }^{[13,14]}$

There are several ways of observing stress distributions. The finite element analysis (FEA) involves dividing a structure into small segments each with specific physical properties. The use of FEA in implant analysis has been widely demonstrated and published. As an important computing tool, the FEA is particularly convenient for evaluating and improving implant design without the risk and expense of real implantation. ${ }^{[15]}$ However, it is important to recognize the effect of implant design, superstructure material type and the effects of the distal cantilever on stress distribution in a FPD. It is not properly documented whether in an implant supported FPD, the effect of the implant design and superstructure material type at the load exerted on the cantilever extension may cause undesirable bone loss.

The aim of this study was to evaluate the stress distribution levels which occur around two different types of dental implants with two different restorative materials as superstructures as cantilever FPDs.

\section{MATERIALS AND METHODS}

This study compared two commercially available dental implants, cylinder type and cylinder with micro threads around implant neck (Sweden Institute Straumann AG, Waldenburg, Switzerland and Astra Tech AB, Mölndal) and two different prosthetic materials (conventional metal ceramic, FRC). Three-dimensional finite element models of a 3-unit cantilever bridge were subjected to $150 \mathrm{~N}$ occlusal loads over functional cusps to evaluate the prosthetic materials and implant designs [Figure 1]. All structures of implants and superstructures' defined contours were scanned using a NextEngine 3D scanner (California, USA).

To evaluate the stress distributions within the bone around dental implants, 3-dimensional FEA was conducted using four mathematical models of unilateral 3-unit cantilever FPDs supported by two implants.

\section{Finite element models}

A graphic processing program (Algor FEMPro V20) was used to construct the mathematical models, consisting of bone, two osseointegrated implants and the FPDs. The bone was modeled as a cancellous core surrounded by $2 \mathrm{~mm}$ thick cortical bone. The diameters and heights

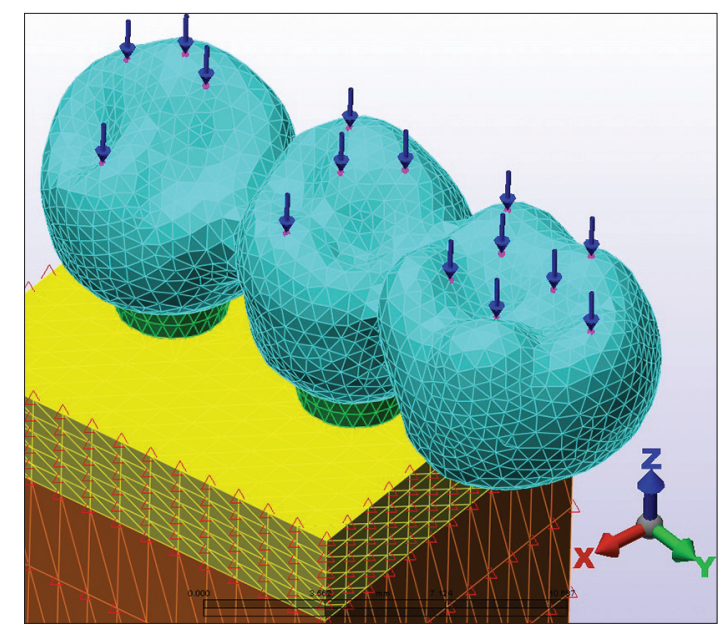

Figure 1: Meshed model with simulated loading condition. The arrows indicate loading points and angles 
of the implants were selected to be comparable in size: $4.0 \mathrm{~mm}$ in diameter and $11 \mathrm{~mm}$ in length for Astra and $4.1 \mathrm{~mm}$ in diameter and $10 \mathrm{~mm}$ in length for ITI implants. These were scanned using a NextEngine 3D scanner and transferred to an interactive finite element program. The implants were inserted $7 \mathrm{~mm}$ apart from each other.

\section{Material properties}

The FPDs were modeled as mandibular first premolar and mandibular second premolar and first molar as a cantilevered superstructure over the implants. Porcelain fused metal (PFM) and FRC were modeled as superstructure materials.

All materials were considered as isotropic, homogenous, and linearly elastic. ${ }^{[16,17]}$ For bone, this enabled the creation of complex models. The elastic properties used in the model were taken from the literature, as shown in Table 1.

\section{Interface conditions}

All interfaces between the materials were assumed to be bonded or osseointegrated. The cement layer between the crown and abutment was too thin to adequately model in the finite element simulation and was considered to be negligible for modeling purposes. ${ }^{[18,19]}$

\section{Loading conditions}

Based on previous reports, a static, vertical load of $150 \mathrm{~N}$ was applied to the model.[18-20] The loads were applied simultaneously over the crowns on functional cusps [Figure 1]. The stress levels were calculated using von Mises stress values.

\section{RESULTS}

Maximum stress levels were shown in Table 2.

\section{Loading on implants with PFM restoration}

When loading on implants with porcelain restorations, the maximum stresses were observed at the cortical bone around the implant adjacent to the cantilever. While the highest von Mises stress concentrations were observed at the cortical bone in both implants, (Micro-thread neck cylinder implant: $10.07 \mathrm{~N} / \mathrm{mm}^{2}$, cylinder implant: $14.62 \mathrm{~N} / \mathrm{mm}^{2}$ ) Stress concentrations around the distant implants (Micro-thread neck cylinder implant: $3.02 \mathrm{~N} / \mathrm{mm}^{2}$, cylinder implant: $6.35 \mathrm{~N} / \mathrm{mm}^{2}$ ) were much lower than the adjacent implant.

The maximum stresses in the cancellous bone were observed at the apical regions of the adjacent implants. Compressive stress concentrations in cancellous bone around the distant implant were lower (Micro-thread neck cylinder implant: $2.01 \mathrm{~N} / \mathrm{mm}^{2}$, cylinder implant: $5.103 \mathrm{~N} / \mathrm{mm}^{2}$ ) [Figures 2-5].

\begin{tabular}{lcc}
$\begin{array}{l}\text { Table 1: Mechanical properties of oral and prosthetic } \\
\text { materials in FEA }\end{array}$ & Modulus of elasticity GPa & Poisson's ratio \\
\hline Metal framework & 86 & 0.33 \\
Feldspathic porcelain & 82.2 & 0.35 \\
Cortical bone & 14 & 0.30 \\
Cancellous bone & 1.37 & 0.30 \\
Composite resin & 14 & 0.24 \\
Fiber & 40 & 0.25 \\
Titanium & 117 & 0.33 \\
\hline
\end{tabular}

FEA-Finite element analysis

\begin{tabular}{|c|c|c|c|c|}
\hline \multicolumn{5}{|c|}{ Table 2: Stress levels } \\
\hline \multirow{3}{*}{$\begin{array}{l}\text { Implant type } \\
\text { Superstructure }\end{array}$} & \multicolumn{4}{|c|}{ Maximum N/mm ${ }^{2}$} \\
\hline & \multicolumn{2}{|c|}{$\begin{array}{l}\text { Cylinder } \\
\text { implant }\end{array}$} & \multicolumn{2}{|c|}{$\begin{array}{l}\text { Cylinder implant } \\
\text { with microthreads }\end{array}$} \\
\hline & Cortical & Cancellous & Cortical & Cancellous \\
\hline Metal porcelain & 14.62 & 5.103 & 10.07 & 2.01 \\
\hline Fiber reinforced & 14.16 & 5.06 & 9.81 & 2.65 \\
\hline
\end{tabular}

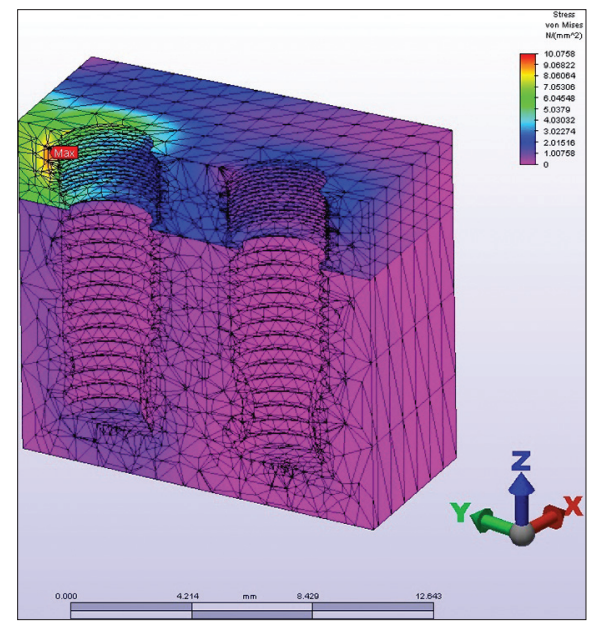

Figure 2: Stress distributions at the cortical site on Astra implants with porcelain restoration

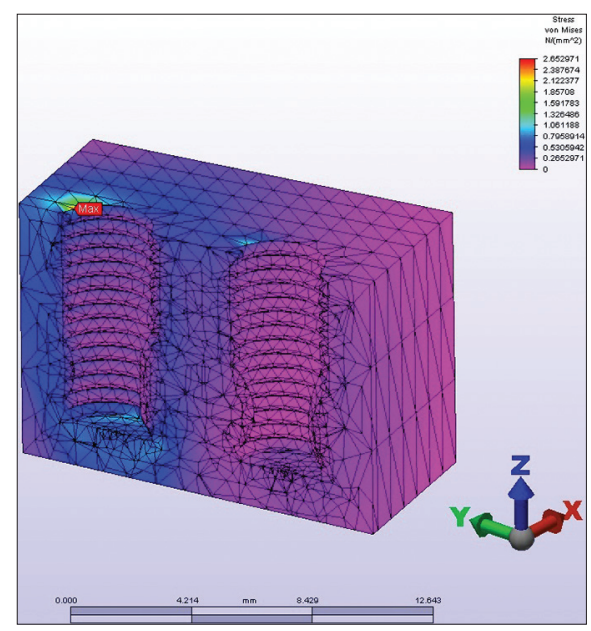

Figure 3: Stress distributions at the cancellous site on Astra implants with porcelain restoration 
Cylinder implant with micro threads around implant neck showed lower stress values than the cylinder implant.

\section{Loading on implants with FRC restoration}

Stresses were concentrated around the implant adjacent to cantilever as with the previous porcelain restoration where stresses in FRC restoration were concentrated around the implant adjacent to the cantilever. Maximum stress (Micro-thread neck cylinder implant: $9.81 \mathrm{~N} / \mathrm{mm}^{2}$, cylinder implant: $14.16 \mathrm{~N} / \mathrm{mm}^{2}$ ) was observed at the cortical bone, around the adjacent implant. The stress levels around the implant distant from the cantilever were lower $\left(3.92 \mathrm{~N} / \mathrm{mm}^{2}\right)$ than the adjacent implant but they were higher than those observed with porcelain restoration (3.02 $\mathrm{N} / \mathrm{mm}^{2}$ ) [Figures 6-9].

The maximum stresses in the cancellous bone were at the apical region of the adjacent implant to the cantilever extension and were considerably lower (Micro-thread neck cylinder implant $2.65 \mathrm{~N} / \mathrm{mm}^{2}$, cylinder implant:

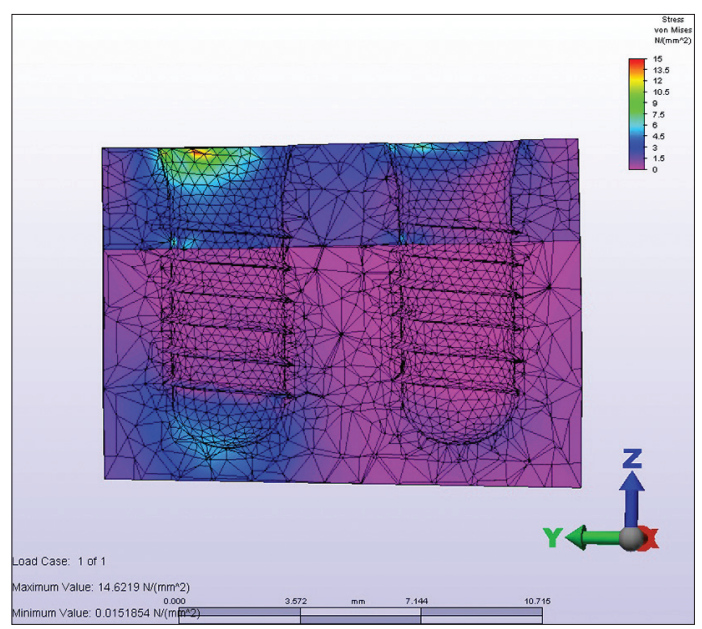

Figure 4: Stress distributions at the cortical site on ITI implants with porcelain restoration

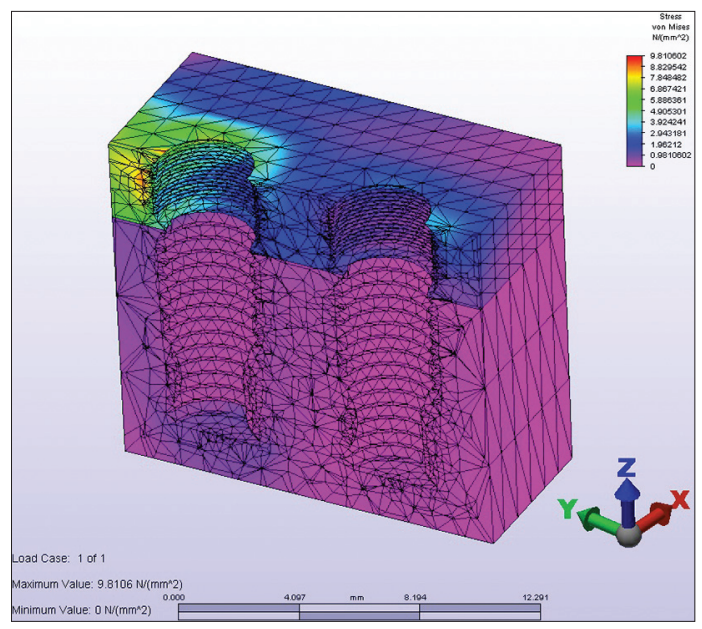

Figure 6: Stress distributions at the cortical site on Astra implants with fiber reinforced composite
$5.06 \mathrm{~N} / \mathrm{mm}^{2}$ ) than in the cortical bone. The stresses were much lower around the mesial implant.

As the stress distribution patterns were similar for both restorative materials, the highest stress values were observed around the cylinder implants. All the stress values observed in the four models indicate that there was a reduction in stress with the micro-thread design.

\section{DISCUSSION}

Different prosthetic designs can be utilized to restore missing teeth. In some situations, it is not possible to use two abutment teeth at each end of the edentulous area to support FPDs. In such a clinical situation, a FPD can be designed with a distal cantilever to replace missing teeth.

Cantilevered ends of fixed implant-supported prostheses increase the load on the first implant nearest to the cantilever arm. ${ }^{[21,22]}$ A previous FEA study demonstrated

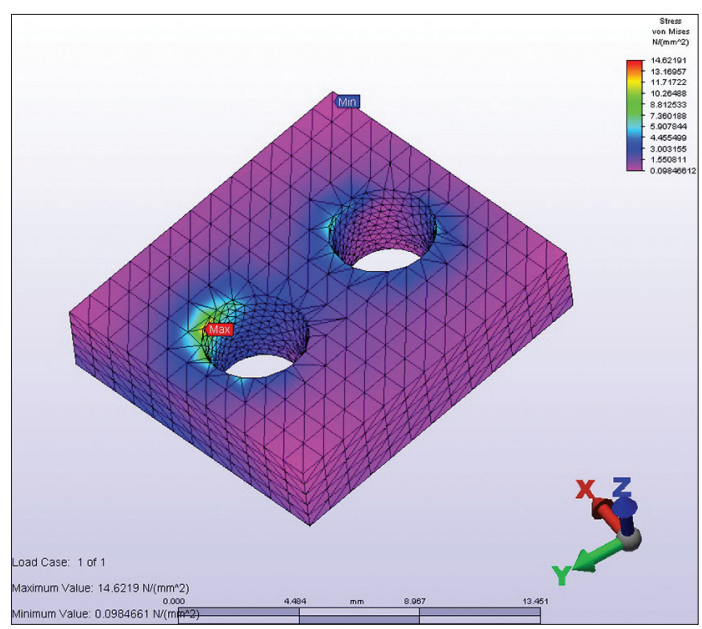

Figure 5: Stress distributions at the cortical site on ITI implants with porcelain restoration occlusal view

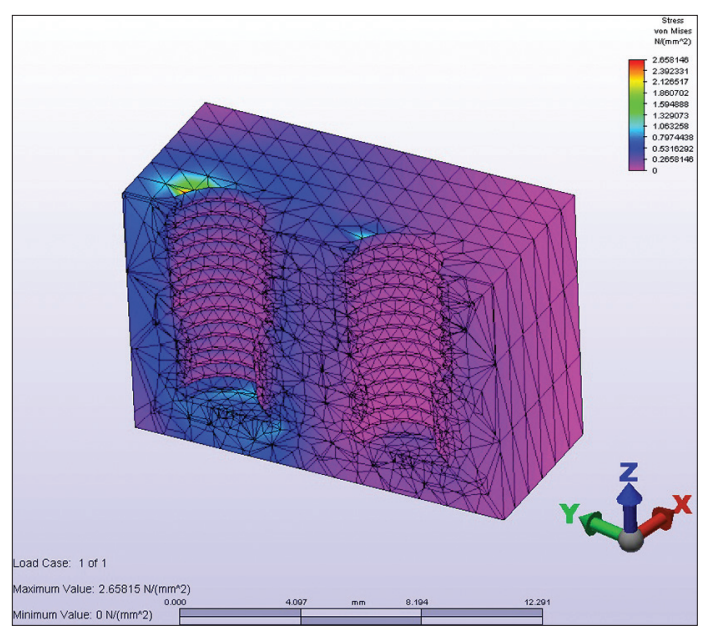

Figure 7: Stress distributions at the cancellous site on Astra implants with fiber reinforced composite 


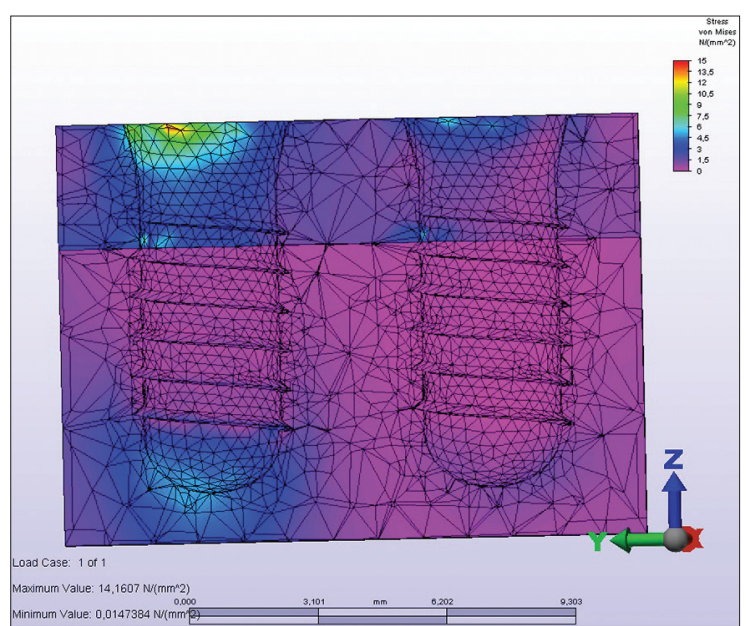

Figure 8: Stress distributions at the cortical site on ITI implants with fiber reinforced composite restoration

that the maximum equivalent stress in an FPD with a central pontic was less than half that of the cantilever FPDs. ${ }^{[23]}$ Cantilever length plays a key role on the stresses around the implants. ${ }^{[24]}$ With increased length of the cantilever increased stress occur around the implants. ${ }^{[25]}$

The results of this study are in accordance with other previous studies, reporting in cantilevered prostheses the most distal implants serve as a fulcrum, and subjected to compression forces, while distant implants suffer tension. ${ }^{[26-28]}$

Metal-porcelain, gold alloys, acrylics and fiber-reinforced composites are used as superstructure materials in implant supported fixed restorations. ${ }^{[29,30]}$ Some researchers reported a more resilient superstructure material would be useful at reducing stresses around the implant by the materials' elastic deformation behaviors. ${ }^{[23,31]}$

On the contrary, there are studies that reported changing the superstructure material did not influence the stress levels. ${ }^{[13,32,33]}$

The results of the present study, it was found that although stress values were lower in FRC restorations, changing the superstructure material did not significantly affect the stress concentration or distribution around the implants, in accordance with the previous studies. Although, the resilient superstructure material (FRC) showed more dislocation, it did not affect the stress intensity. This finding may be related to the selected loading type in the present study. In the literature, it is stated that under static loading, changing the resilience properties of different superstructure materials does not result in significant differences in stress concentrations and distributions around the implants. ${ }^{[13,19,34,35]}$ The advantages of using resilient materials become apparent under dynamic loads and impact forces. ${ }^{[13,33,36]}$

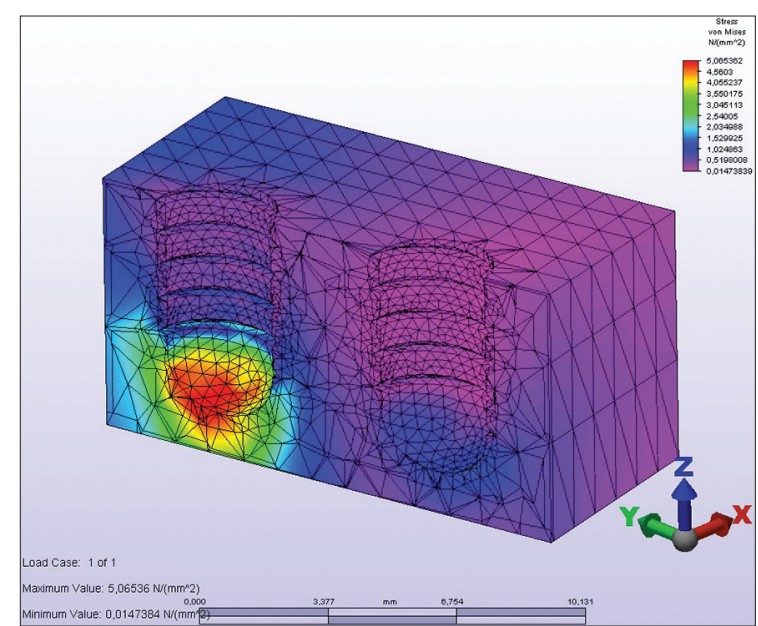

Figure 9: Stress distributions at the cancellous site on ITI implants with fiber reinforced composite restoration

The current study investigated the most appropriate material and implant design for an implant supported cantilever bridge, recognizing the uncertainty of the implant design, the effects of differing restorative materials and of the distal cantilever on stress distribution in a FPD. The FEA used in the present study is one of the most frequently used methods in stress analysis both in industry and science. ${ }^{[37]}$ The structures in this study were assumed to be homogenous and isotropic and to possess linear elasticity. However, the mandible is in fact transversely isotropic and not homogenous, and is especially subjected to functional elastic deformations originating from masticatory forces, as the bone is a living tissue. ${ }^{[24,38]}$ Furthermore, implants were simulated as $100 \%$ osseointegrated, as in previous studies. ${ }^{[18-20,32,39,40]}$ However histomorphometric data have indicated that there is never $100 \%$ bone-implant contact. Therefore, the inherent limitations of FEA must be acknowledged.

The average maximum occlusal force was approximately $200 \mathrm{~N}$ for premolars and molars. ${ }^{[41]}$ Therefore, a mean occlusal force was selected, considering these values. A load of $150 \mathrm{~N}$ was applied to the FEA models. However, it may not be necessary for this force to exactly match the reality, because standardization between conditions has been ensured in the current study and the conditions have been compared qualitatively with each other.

The loads over implants show differences according to the localization. The risk of overloading implants increases at the posterior regions. ${ }^{[42]}$ Most serious stresses occur when cantilever restorations are used. However, cantilever extensions are used in many cases, especially, when it is not possible to use another implant. Pull-out force at cantilever extensions, is increased up to $40 \%$ of the vertical load. ${ }^{[38]}$ In order to minimize the cantilever effect, occlusal table should be reduced, occlusal contacts should be reduced, and contacts at lateral movements should be eliminated. ${ }^{[43]}$ 
Bone loss is not always due to the implant itself but, in dental implant design, it is important to determine the implant shape that maximizes anchorage strength within the bone. According to general engineering, this is achieved by using an implant geometry that minimizes the peak bone stress caused by standardized load upon the implant. ${ }^{[3]}$

Palmer et al. reported remarkably high marginal bone levels for an implant, provided with retention elements at the neck. ${ }^{[4]}$ Lee et al. and Hansson suggested that retention elements at the implant neck would increase the axial load that an implant can support. ${ }^{[3,45,46]}$ Compared to a thread of standard dimensions, a small thread gives the additional advantage of increasing the axial stiffness of the implant, resulting in an additional reduction of the peak interfacial shear stress. For most systems, this neck portion of the implant is smooth. Various designs include parallel, converging and diverging sides. It has been shown that although peak principal stress values were higher around a micro-threaded implant, peri-implant bone volume exhibited smaller strain level compared to a smooth implant. ${ }^{[47]}$ Recently, Ferraz et al. stated that the implant with micro-threads showed higher stress concentration for cortical bone in comparison with the smooth implant, an lower stress concentration for cancellous bone. ${ }^{[48]}$ The results of these studies are in accordance with the present study.

In the present study, the implant design was shown to affect the stress intensity or distribution around the implants. The highest stress values were observed at the cortical bone. Lower stress levels were observed around the cylinder with micro-threads type implants. AstraTech micro-thread design reduced the stress that was distributed throughout the implant body, but the peak stress was still present on implant neck. The ITI/Straumann cylindrical implant design was shown to successfully transfer the stress throughout the implant body and to the apical region, but the stress values were higher than those seen in the AstraTech design.

Within the limitations of this study, changing the superstructure material did not affect the stress intensity or distribution, but implant macro-design affected the stress distribution under static loading.

\section{REFERENCES}

1. Waters NE. Some mechanical and physical properties of teeth. Symp Soc Exp Biol 1980;34:99-135.

2. Brunski JB. In vivo bone response to biomechanical loading at the bone/dental-implant interface. Adv Dent Res 1999;13:99-119.

3. Hansson S. The implant neck: Smooth or provided with retention elements: A biomechanical approach. Clin Oral Implants Res 1999;10:394-405.

4. Marin C, Granato R, Suzuki M, Janal MN, Gil JN, Nemcovsky C, et al. Biomechanical and histomorphometric analysis of etched and non-etched resorbable blasting media processed implant surfaces:
An experimental study in dogs. J Mech Behav Biomed Mater 2010;3:382-91.

5. Coelho PG, Suzuki M, Guimaraes MV, Marin C, Granato R, Gil JN, et al. Early bone healing around different implant bulk designs and surgical techniques: A study in dogs. Clin Implant Dent Relat Res 2010;12:202-8.

6. Bonfante EA, Granato R, Marin C, Suzuki M, Oliveira SR, Giro G, et al. Early bone healing and biomechanical fixation of dual acid-etched and as-machined implants with healing chambers: An experimental study in dogs. Int $\mathrm{J}$ Oral Maxillofac Implants 2011;26:75-82.

7. Bevilacqua M, Tealdo T, Menini M, Pera F, Mossolov A, Drago C, et al. The influence of cantilever length and implant inclination on stress distribution in maxillary implant-supported fixed dentures. J Prosthet Dent 2011;105:5-13.

8. Stanford CM. Surface modification of biomedical and dental implants and the processes of inflammation, wound healing and bone formation. Int J Mol Sci 2010;11:354-69.

9. Ciftçi Y, Canay S. The effect of veneering materials on stress distribution in implant-supported fixed prosthetic restorations. Int J Oral Maxillofac Implants 2000;15:571-82.

10. Ruyter IE, Ekstrand K, Bjork N. Development of carbon/graphite fiber reinforced poly (methyl methacrylate) suitable for implant-fixed dental bridges. Dent Mater 1986;2:6-9.

11. Behr M, Rosentritt M, Lang R, Chazot C, Handel G. Glass-fibre-reinforced-composite fixed partial dentures on dental implants. J Oral Rehabil 2001;28:895-902.

12. Meriç G, Dahl JE, Ruyter IE. Physicochemical evaluation of silica-glass fiber reinforced polymers for prosthodontic applications. Eur J Oral Sci 2005;113:258-64.

13. Stegaroiu R, Khraisat A, Nomura S, Miyakawa O. Influence of superstructure materials on strain around an implant under 2 loading conditions: A technical investigation. Int $\mathrm{J}$ Oral Maxillofac Implants 2004;19:735-42.

14. Kunavisarut C, Lang LA, Stoner BR, Felton DA. Finite element analysis on dental implant-supported prostheses without passive fit. J Prosthodont 2002;11:30-40.

15. Cook SD, Klawitter JJ, Weinstein AM. A model for the implant-bone interface characteristics of porous dental implants. J Dent Res 1982;61:1006-9.

16. Huang HL, Huang JS, Ko CC, Hsu JT, Chang CH, Chen MY. Effects of splinted prosthesis supported a wide implant or two implants: A three-dimensional finite element analysis. Clin Oral Implants Res 2005; 16:466-72.

17. Kitamura E, Stegaroiu R, Nomura S, Miyakawa O. Biomechanical aspects of marginal bone resorption around osseointegrated implants: Considerations based on a three-dimensional finite element analysis. Clin Oral Implants Res 2004;15:401-12.

18. Yokoyama S, Wakabayashi N, Shiota M, Ohyama T. The influence of implant location and length on stress distribution for three-unit implant-supported posterior cantilever fixed partial dentures. J Prosthet Dent 2004;91:234-40.

19. Eskitascioglu G, Usumez A, Sevimay M, Soykan E, Unsal E. The influence of occlusal loading location on stresses transferred to implant-supported prostheses and supporting bone: A three-dimensional finite element study. J Prosthet Dent 2004;91:144-50.

20. Sato Y, Shindoi N, Hosokawa R, Tsuga K, Akagawa Y. Biomechanical effects of double or wide implants for single molar replacement in the posterior mandibular region. J Oral Rehabil 2000;27:842-5.

21. Gunne J, Rangert B, Glantz PO, Svensson A. Functional loads on freestanding and connected implants in three-unit mandibular prostheses opposing complete dentures: An in vivo study. Int J Oral Maxillofac Implants 1997;12:335-41.

22. Skalak R. Biomechanical considerations in osseointegrated 
prostheses. J Prosthet Dent 1983;49:843-8.

23. Stegaroiu R, Sato T, Kusakari H, Miyakawa O. Influence of restoration type on stress distribution in bone around implants: A three-dimensional finite element analysis. Int $\mathrm{J}$ Oral Maxillofac Implants 1998;13:82-90.

24. Bevilacqua M, Tealdo T, Pera F, Menini M, Mossolov A, Drago C, et al. Three-dimensional finite element analysis of load transmission using different implant inclinations and cantilever lengths. Int $J$ Prosthodont 2008;21:539-42.

25. Rubo JH, Capello Souza EA. Finite-element analysis of stress on dental implant prosthesis. Clin Implant Dent Relat Res 2010;12:105-13.

26. Jacques LB, Moura MS, Suedam V, Souza EA, Rubo JH. Effect of cantilever length and framework alloy on the stress distribution of mandibular-cantilevered implant-supported prostheses. Clin Oral Implants Res 2009;20:737-41.

27. Rubo JH, Souza EA. Finite element analysis of stress in bone adjacent to dental implants. J Oral Implantol 2008;34:248-55.

28. Suedam V, Souza EA, Moura MS, Jacques LB, Rubo JH. Effect of abutment's height and framework alloy on the load distribution of mandibular cantilevered implant-supported prosthesis. Clin Oral Implants Res 2009;20:196-200.

29. Kawano F, Ohguri T, Ichikawa $T$, Matsumoto $N$. Influence of thermal cycles in water on flexural strength of laboratory-processed composite resin. J Oral Rehabil 2001;28:703-7.

30. Kase HR, Tesk JA, Case EC. Elastic constants of two dental porcelains. J Mater Sci 1985;20:524-31.

31. Erkmen E, Meriç G, Kurt A, Tunç Y, Eser A. Biomechanical comparison of implant retained fixed partial dentures with fiber reinforced composite versus conventional metal frameworks: A 3D FEA study. J Mech Behav Biomed Mater 2011;4:107-16.

32. Cehreli MC, Akça K, Iplikçioğlu H. Force transmission of one- and two-piece morse-taper oral implants: A nonlinear finite element analysis. Clin Oral Implants Res 2004;15:481-9.

33. Bassit $\mathrm{R}$, Lindström $\mathrm{H}$, Rangert $\mathrm{B}$. In vivo registration of force development with ceramic and acrylic resin occlusal materials on implant-supported prostheses. Int $J$ Oral Maxillofac Implants 2002; 17:17-23.

34. Wang TM, Leu LJ, Wang J, Lin LD. Effects of prosthesis materials and prosthesis splinting on peri-implant bone stress around implants in poor-quality bone: A numeric analysis. Int J Oral Maxillofac Implants 2002;17:231-7.

35. Ciftçi Y, Canay S. Stress distribution on the metal framework of the implant-supported fixed prosthesis using different veneering materials. Int J Prosthodont 2001;14:406-11.
36. Gracis SE, Nicholls JI, Chalupnik JD, Yuodelis RA. Shock-absorbing behavior of five restorative materials used on implants. Int $\mathrm{J}$ Prosthodont 1991;4:282-91.

37. Himmlová L, Dostálová T, Kácovský A, Konvicková S. Influence of implant length and diameter on stress distribution: A finite element analysis. J Prosthet Dent 2004;91:20-5.

38. Misch CE. Contemporary Implant Dentistry. Missouri: Mosby; 1999. p. 151-61.

39. Akça K, Iplikçioğlu H. Finite element stress analysis of the influence of staggered versus straight placement of dental implants. Int J Oral Maxillofac Implants 2001;16:722-30.

40. Barbier L, Vander Sloten J, Krzesinski G, Schepers E, Van der Perre G. Finite element analysis of non-axial versus axial loading of oral implants in the mandible of the dog. J Oral Rehabil 1998;25:847-58.

41. Mericske-Stern R, Assal P, Mericske E, Bürgin W. Occlusal force and oral tactile sensibility measured in partially edentulous patients with ITI implants. Int J Oral Maxillofac Implants 1995;10:345-53.

42. Sahin S, Cehreli MC, Yalçin E. The influence of functional forces on the biomechanics of implant-supported prostheses - A review. J Dent 2002;30:271-82.

43. Jeong CM, Caputo AA, Wylie RS, Son SC, Jeon YC. Bicortically stabilized implant load transfer. Int $J$ Oral Maxillofac Implants 2003; 18:59-65.

44. Palmer RM, Smith BJ, Palmer PJ, Floyd PD. A prospective study of Astra single tooth implants. Clin Oral Implants Res 1997;8:173-9.

45. Lee DW, Choi YS, Park KH, Kim CS, Moon IS. Effect of microthread on the maintenance of marginal bone level: A 3-year prospective study. Clin Oral Implants Res 2007;18:465-70.

46. Schrotenboer J, Tsao YP, Kinariwala V, Wang HL. Effect of microthreads and platform switching on crestal bone stress levels: A finite element analysis. J Periodontol 2008;79:2166-72.

47. Hudieb MI, Wakabayashi N, Kasugai S. Magnitude and direction of mechanical stress at the osseointegrated interface of the microthread implant. J Periodontol 2011;82:1061-70.

48. Ferraz CC, Anchieta RB, de Almeida EO, Freitas AC Jr, Ferraz FC, Machado LS, et al. Influence of microthreads and platform switching on stress distribution in bone using angled abutments. J Prosthodont Res 2012;56:256-63.

How to cite this article: Culhaoglu AK, Ozkir SE, Celik G, Terzioglu H. Comparison of two different restoration materials and two different implant designs of implant-supported fixed cantilevered prostheses: A 3D finite element analysis. Eur J Gen Dent 2013;2:144-50.

Source of Support: Nil, Conflict of Interest: None declared. 